\title{
Sustainable mobility planning in the tourist centres: the estimation of transport demand
}

\author{
P. Zito, G. Salvo \& L. La Franca \\ Department of Transport Engineering, University of Palermo, \\ Viale delle Scienze, Edificio 8, 90128 Palermo, Italy
}

\begin{abstract}
The aim of the paper is to provide a framework for sustainable mobility planning in tourist centres. In particular, the focus is on estimating the potential non-motorised transport demand and to design the supply of sustainable transport modes (as such as: transit, cycling and walking). The study area is the tourist area of San Vito Lo Capo, the famous historical and swimming centre of Sicily. In this context we have carried out a stated preference survey to evaluate the potential demand of non-motorised transport modes, taking into account a sample of the population. Thus, we have submitted a questionnaire, considering the choice in a competitive scenario of the non-motorised transport modes. The survey was carried out in the period of June-July 2006. Furthermore a multinomial logit model has been calibrated.
\end{abstract}

Keywords: sustainable mobility, tourist centres, transport demand.

\section{Introduction}

The pedestrian and bike mobility needs of comfort, safety and secure green paths attract more users of private transport. The bicycle is an individual nonmotorised mode with low access costs and high efficiency in the use of road space; it is also associated to benefits in terms of health, the environment and quality of life. In order to help alleviate the serious pollution and increasingly annoying congestion problems of cities, the regional government has made several attempts to implement cycle-ways in Sicily during recent years (by nonmotorised mobility plane in Sicily, 2005). This plane foresees the realization of greenways along tourist cycle paths by the re-use of old disused railways and tourist roads with low traffic levels. These attempts have failed notoriously because of the following factors (Ortúzar et al. [10]): 
a. the lack of safety experienced by cyclists within a noisy, polluting and undisciplined mass of motorised vehicles who show scarce respect for cyclists; there is now enough evidence that cycle lanes (i.e., cycle paths painted on the pavement but not segregated from the traffic) are not respected by car or bus drivers;

b. the lack of proper bicycle shelter facilities to leave the bikes. Several systems have been tried, especially near Transit/Railway stations in order to encourage transfers, but have failed because of the lack of safety felt at the site or about its operation;

c. the cultural/idiosyncrasy bias against the use of bikes as a means of transport caused mainly by years of (funny and well-done) car dealers' propaganda television sketches ridiculing the bicycle;

In Sicily, citizens have a short tradition in the use of the cycle, conversely to the north of Italy, due to social and safety biases that have hindered cycle use. Nevertheless, in the tourist and natural areas, this mode can attract a relevant potential transport demand.

Both in the US and Europe (rather unsuccessful) efforts to alleviate urban congestion through park-and-ride and car-pool programs in the 1970s and 1980s largely ignored the possibility of using the bicycle as an alternate transport mode. However, although the impact of cycling in urban transport has not been great (with exceptions such as Holland and some cities in Germany) a fair amount of knowledge about bicycle use and cycle-way design has been collected in the recent decades (HCM [1], Botma [2]; Cleary [3]; Downing [5]; Forester [6]; Hudson [7]; Newman and Bebendorf [9]; Replogle [13]; Waldman [14]). For example, common sense factors that have been proved to affect bicycle use are: distance (length of trip and travel time); gradient or hilliness, and safety (absence of safe places to ride, lack of secure bike parking facilities and fear of crime).

Now, despite the growing literature on cycling it should be noted that very few studies have tried to estimate the demand for cycling and the benefits of new cycle facilities in recent decades. Ortúzar, [8] estimated the demand for a cycleway network, showing that the trip length is a fundamental variable. Unfortunately, it is recognized that cycling can be one of the least safe modes of travel for the user. Parking et al. [12] and Davis [4] carried out studies to identify the perceived cycling risk and the acceptability of the route.

The main task of this paper is to show that the framework for transport demand estimation is quite different for small tourist centres or relevant naturalistic areas, where the transport demand patterns (relevant attributes) for non-motorised modes are unlike ones of big cities or Central Business Districts. First of all the distance, for small tourist centres the $\mathrm{O} / \mathrm{D}$ relations are on short distances and the trip usually involves one transport mode (i.e. bus, walking, cycling; the private car is usually discouraged by limited traffic zones and parking prices); whereas for big cities, the trip can be over medium/long distances, involving one or more change of transport modes.

The second and no less relevant aspect concerns the type of transport demand. The tourist centres are characterised by periodic fluctuations of transport demand (i.e. in summer the population of these centres increases up to many times the 
population in the winter period). Thus, the population is characterized by residents and non-residents for holiday, leisure and cultural tourism, which are the bulk in peak periods. For these, when they have arrived at the destination, the trip time for tours/excursions is not a very significant attribute, conversely, the waiting times are very important attributes.

The purposes of the analysis are: to reduce congestion in the road network close to the swimming zone and thus to rationalise the stream of people; to improve the accessibility to the tourist centre by a park and ride policy. For these, we have submitted a questionnaire, considering the choice in a competitive scenario of the non-motorised transport modes. The survey was carried out in the period of June-July 2006. Furthermore a multinomial logit model has been calibrated. Finally a preliminary design has been proposed.

\section{Study area}

The territory of San Vito Lo Capo has many resources. The nature of the area with a spread entropic action has strongly influenced the land use. The area is characterised by: urban centres of San Vito Lo Capo, Castelluzzo and Macari; mountainous systems on which are situated the wildlife reserves of Zingaro and Monte Cofano; a coastal system with the coastal beach, historical archaeological, architectural and natural sites.

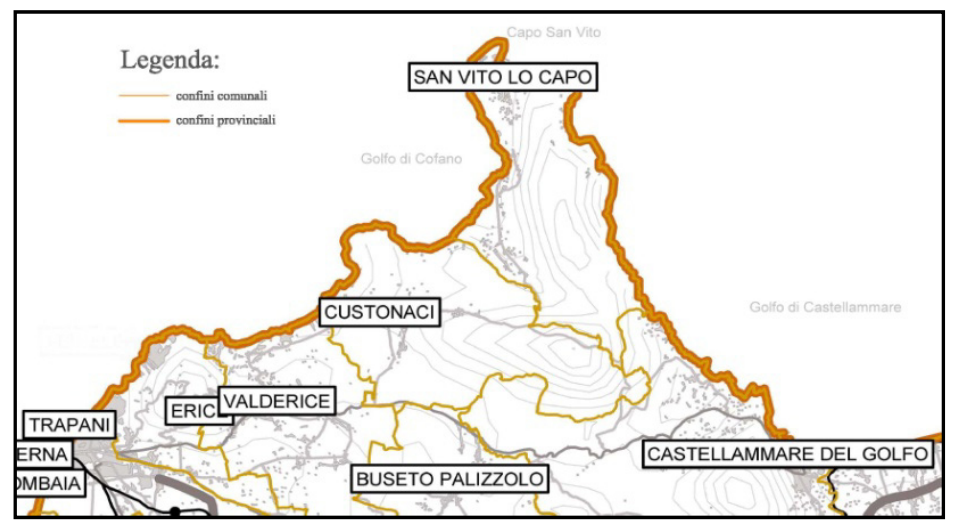

Figure 1: $\quad$ Territory of San Vito Lo Capo.

The country of San Vito Lo Capo has a surface of about of $60 \mathrm{~km}^{2}$. It has a resident population of 3,915 inhabitants whereas Macari and Castelluzzo have a population of 297 and 1,010 inhabitants respectively. Thus, the population density is about 65 inhabitants $/ \mathrm{km}^{2}$. The road accessibility of the territory is characterised by road SP Trapani-San Vito Lo Capo, which on one side joins the state road S.S. 187 with the highway A29. On the other side it connects with Trapani.

Moreover, other transport systems allow one to reach the territory of San Vito Lo Capo by railway at Palermo-Trapani, via the airports of Birgi and Falcone- 
Borsellino and the ports of Trapani and San Vito Lo Capo. The territory is mostly flat and is characterised by an average slope of less than $3 \%$ and only on some short paths it can be about $6 \%$. The non-motorised mobility plane in Sicily identifies some cycle paths but it does not realize a real cycle network. Only in the case of San Vito Lo Capo can this happen. In fact, it foresees in the territory the realization of two cycle paths: Bonagia-Custonaci for $16 \mathrm{~km}$ and San Vito Lo Capo-Castelluzzo for $8 \mathrm{~km}$. Potentially, San Vito Lo Capo can become a cycle service centre, which would allow one to go seamless from Castellamare up to Trapani, by cycle. For this reason, we have carried out the analysis of the cycle potential demand in this area.

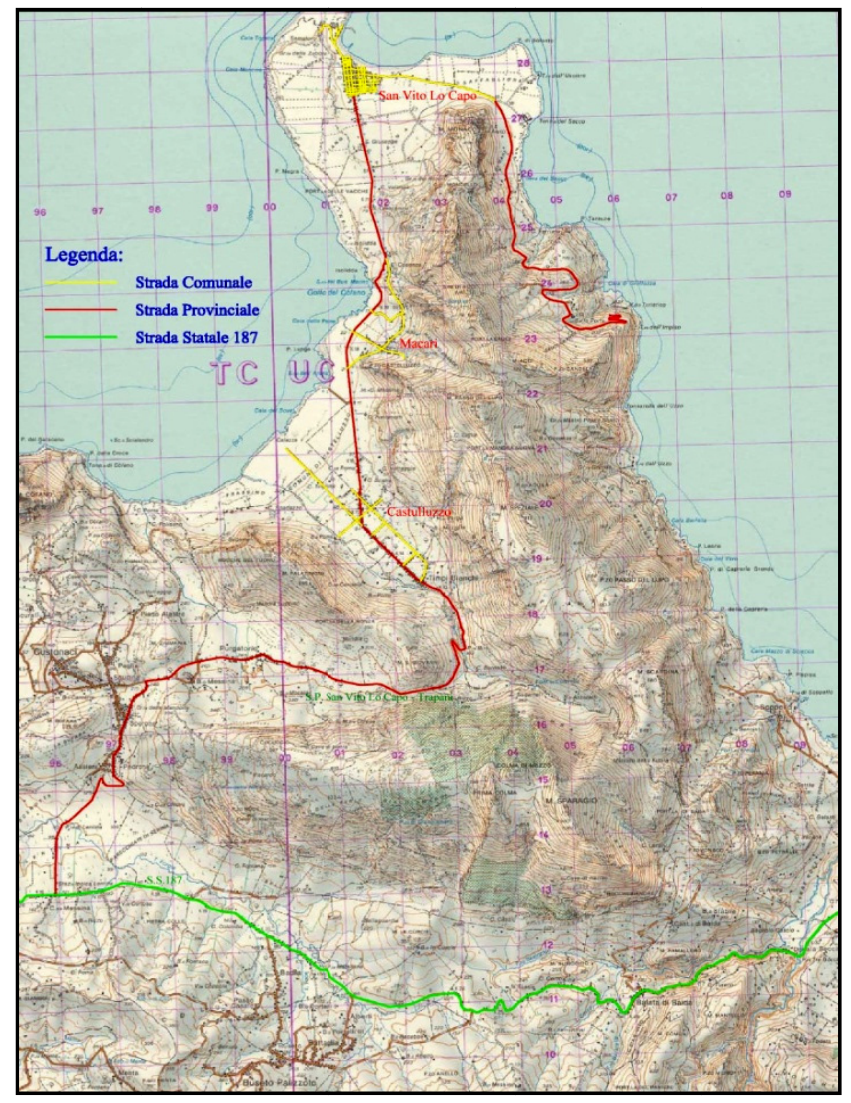

Figure 2: The road network of the territory.

In the summer period, the population can increase up to 370,000 persons per days' number of stay. It is clear that in the peak period congestion and overcrowding rise, causing high waiting times and annoyance for citizens. The City Council of San Vito Lo Capo has already for some years introduced a parking pricing policy and a Limited Traffic Area (LTA). The urban area has been divided into six zones (from $A$ to $E$ and $L T A$ ) for different categories of 


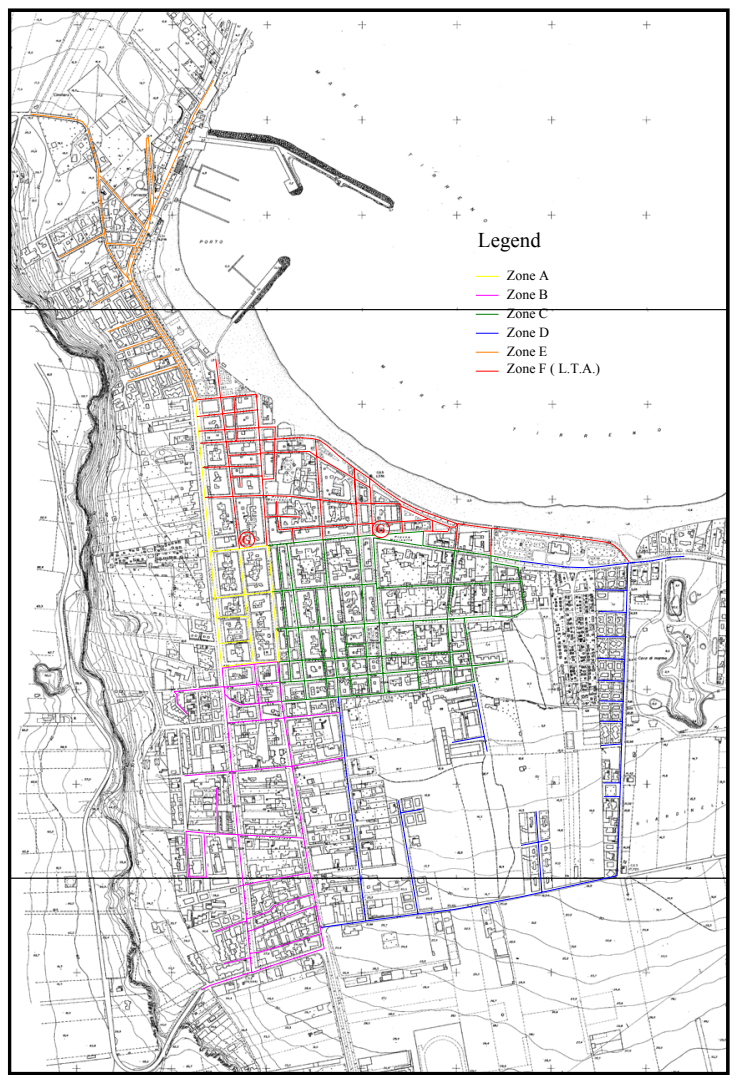

Figure 3: $\quad$ Parking zones.

citizens: residents; owners of summer residences; long period holidays; commuters; occasional visitors or short period holidays. The access to the parking is paid by a card-pass for different categories.

Further, other external parking places have been realized in the urban area for a whole parking supply of 3,000 car places. The City Council together with the creation of external parking places has created two shelter bus lines to connect the external parking places with the urban centre and the beach. The public transport is free of charge. The bus line 1 runs a closed ring of $2.4 \mathrm{~km}$ with a frequency of 15 minutes and a transport demand of 400 passengers per hour for the peak hour more than the line capacity of about $200 \mathrm{pass} / \mathrm{h}$ (related to the bus capacity of 50 passengers for 4 trips per hour). The bus line 2 runs about $3.8 \mathrm{~km}$ with a frequency of 24 minutes.

\section{The survey}

A stated preference survey was carried out submitting a questionnaire to the stratified suitable sample of potential users. The questionnaire has been 


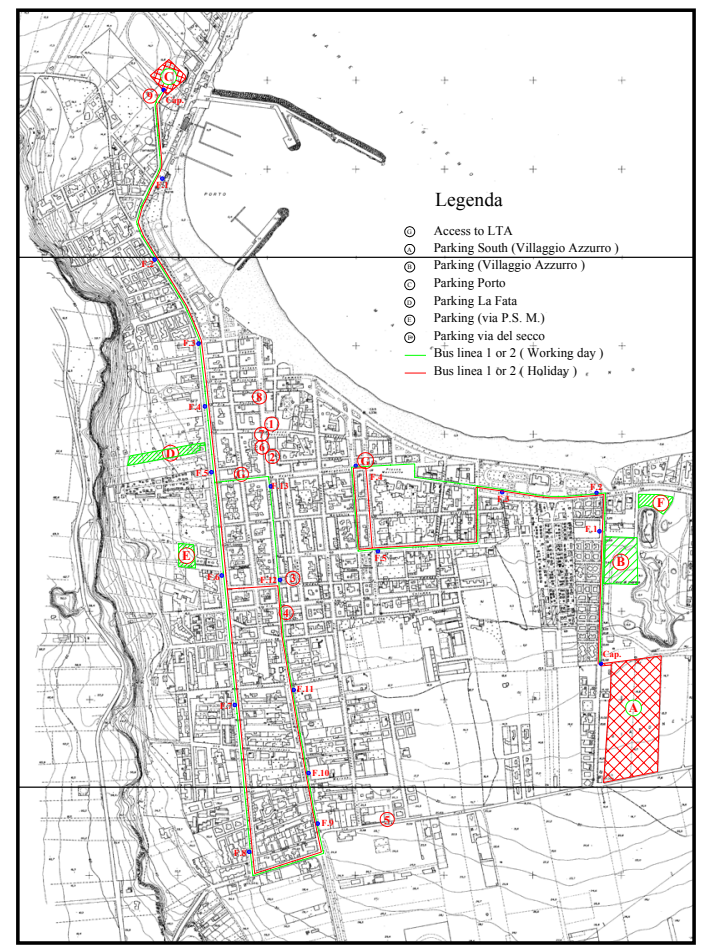

Figure 4: $\quad$ Bus lines 1 and 2.

designed and split into two sections. In the first section the decision-maker provides socioeconomic and transport mode information in order to understand the influence of its behavioural habits on the modal choice. In the second section, after a brief description of the various transport modes, the decision maker states their preference among different choice alternatives on the basis of some attributes regarding the service level of transport modes, whose levels have been determined by analysis of reality and exploration of the scientific literature. The population is composed of about 4,000 people. The sample interviewed has been $1 \%$ of the population. The questionnaire was split into urban and extra-urban trips. The proposed choice alternatives for urban trips are: walking; cycling; public transport. The identification of attributes and of their levels represents the most important task since their choice can strongly influence the significance of outcomes of the stated preference analysis. The attributes identified are: mean trip time; daily cycle renting cost; cycle lane. In this case study it has been decided to assign two levels for any attribute. The values of the levels have been individuated analyzing real paths for each urban trip. By establishing the number of attributes $(t=3)$ and the number of levels of every attribute $(n=2)$, it has been possible to determine the complete factorial plan (composed of $n^{t}=2^{3}=8$ scenarios). The choice alternatives for extra-urban trips are: cycling; public transport; private car; motorbike. The attributes identified are: daily cycle rental 
cost; cycle lanes; mean slope; car parking cost. The complete factorial plan is composed of $n^{t}=2^{4}=16$ scenarios, reduced to 8 scenarios by the procedure of Kocur et al. [8], assuming the irrelevance of interactions between attributes. Each decision-maker has reported on the questionnaire the choice between the competitive alternatives for each scenario. Among choice modalities (choice, ranking and rating) available to the designer of the experiment, the choice has been chosen because it is simpler in the elaboration and also in the indication of the preference.

\section{The demand models}

The main aim of this study has been the calibration of two demand multinomial logit models able to estimate the potential demand of the cycling mode, changing the attributes cycle renting cost, mean slope and cycle lane. In order to calibrate the demand models, the stated preference technique has been used to carry out a survey on the individuated sample. The utility functions of the competitive alternatives were (for urban trips):

$$
\begin{gathered}
U_{W}=\beta_{1} \cdot \text { lane }_{W}+A_{W} ; \\
U_{C}=\beta_{4} \cdot \operatorname{cost}_{C}+\beta_{1} \cdot \text { lane }_{C}+\beta_{2} \cdot \operatorname{sex}+\beta_{3} \cdot \operatorname{age}+\beta_{5} \cdot \frac{N_{b}}{N_{c}}+A_{C} ; \\
U_{\text {bus }}=\beta_{4} \cdot \operatorname{cost}_{\text {bus }}
\end{gathered}
$$

Let $U_{W}$ be the walk utility function; $U_{C}$ the bicycle utility function; $U_{b u s}$ the bus public transport utility function; lane reserved paths $(0=$ yes, $1=$ no, walk, cycle); $\mathrm{N}_{\mathrm{b}} / \mathrm{N}_{\mathrm{c}}$ the number of cycles per person; Age = decision-makers' age (class 1 range less than 20 years old; class 2 range 20-40 years old; class 3 range 40 60 years old; class 4 range more than 60 years old); $A_{W}$ the walk specific attribute; $A_{C}$ the bicycle specific attribute; sex the gender $(1=$ male, $0=$ female $)$; cost the daily cost of transport modes; $\beta_{1} \div \beta_{5}$ coefficients of the utility functions achieved by the calibration process. Whereas, the utility functions of the competitive alternatives were (for extra-urban trips):

$$
\begin{gathered}
U_{C}=\beta_{1} \cdot \operatorname{cost}_{C}+\beta_{3} \cdot \text { lane }_{C}+\beta_{4} \cdot \text { age }+\beta_{6} \cdot \frac{N_{b}}{N_{c}}+A_{C} ; \\
U_{m}=\beta_{1} \cdot \operatorname{cost}_{m}+\beta_{2} \cdot \operatorname{cost}_{\text {Park }, m}+A_{m} ; \\
U_{c a r}=\beta_{1} \cdot \operatorname{cost}_{c a r}+\beta_{2} \cdot \operatorname{cost}_{\text {Park }, a r}+\beta_{5} \cdot \frac{N_{a}}{N_{c}}+A_{c a r} ; \\
U_{b u s}=\beta_{1} \cdot \operatorname{cost}_{\text {bus }}
\end{gathered}
$$

Let $U_{c a r}$ be the car utility function; $U_{m}$ the motorbike utility function; $A_{m}$ the motorbike specific attribute; $A_{\text {car }}$ the car specific attribute; cost $_{\text {Park }}$ the daily cost of parking; $\mathrm{N}_{\mathrm{a}} / \mathrm{N}_{\mathrm{c}}$ the number of cars per person; $\beta_{1} \div \beta_{6}$ coefficients of the utility functions. The calibration of the logit models has been made by the maximum likelihood technique using the Limdep ${ }^{\circledR} 8.0$ software. The results of the calibration process are reported in tables 1 and 2 . 
Table 1: $\quad$ The urban trip calibration process.

\begin{tabular}{||l|c|c|c|c||}
\hline \hline Attributes & Coefficients & Standard Error & $t$ - ratio & $P$ - value \\
\hline \hline cost & -0.2475 & 0.0290 & -8.506 & 0.0000 \\
\hline lane & -0.4808 & 0.1411 & -3.407 & 0.0007 \\
\hline sex & -0.4231 & 0.1437 & -2.943 & 0.0033 \\
\hline age & -0.3382 & 0.0890 & -3.798 & 0.0001 \\
\hline$N_{b} / N_{c}$ & 0.4924 & 0.1748 & 2.817 & 0.0048 \\
\hline$A_{W}$ & 0.8269 & 0.0783 & 10.551 & 0.0000 \\
\hline$A_{C}$ & 2.1723 & 0.3524 & 6.164 & 0.0000 \\
\hline$\chi^{2}[5]$ & 120.1438 Significance $\left(\chi^{2}\right)=1.00000$ \\
\hline
\end{tabular}

Table 2: $\quad$ The extra-urban trip calibration process.

\begin{tabular}{||l|c|c|c|c||}
\hline Attributes & Coefficients & Standard Error & $t$-ratio & $P$ - value \\
\hline \hline cost & -0.363563 & 0.033967 & -10.703 & 0.0000 \\
\hline cost $_{\text {Park }}$ & -0.410034 & 0.021877 & -18.743 & 0.0000 \\
\hline lane & -0.716519 & 0.146037 & -4.906 & 0.0000 \\
\hline age & -0.480231 & 0.099644 & -4.819 & 0.0000 \\
\hline$N_{a} / N_{c}$ & -0.658048 & 0.239315 & -2.750 & 0.0060 \\
\hline$N_{b} / N_{c}$ & 0.955675 & 0.237799 & 4.019 & 0.0001 \\
\hline$A_{C}$ & -0.292933 & 0.299053 & -0.980 & 0.3273 \\
\hline$A_{m}$ & 0.212631 & 0.123664 & 1.719 & 0.0855 \\
\hline$A_{\text {car }}$ & 2.984370 & 0.211427 & 14.115 & 0.0000 \\
\hline$\chi^{2}[6]$ & 636.34957 & Significance $\left(\chi^{2}\right)=1.00000$ \\
\hline \hline
\end{tabular}

The results of the calibration process show the correctness of the coefficients' sign whereas the p-value shows the significance of each attribute. The total significance of the demand model is shown by $\chi^{2}$ test. Moreover, useful information is provided by the elasticity of the attribute daily cycle renting cost related to the alternative bicycle. The direct elasticity is the effect due to a change of the independent variable on the change of the dependent one. We have estimated, by calibrated logit models, a reduction of about 30\% (29.5\% for urban trips and $30.80 \%$ for extra-urban trips) of the bicycle choice probability for an increase of $1 \%$ of the daily cycle renting cost. Figures 5 and 6 show the probability choices of different modes in term of the daily cycle renting cost. 


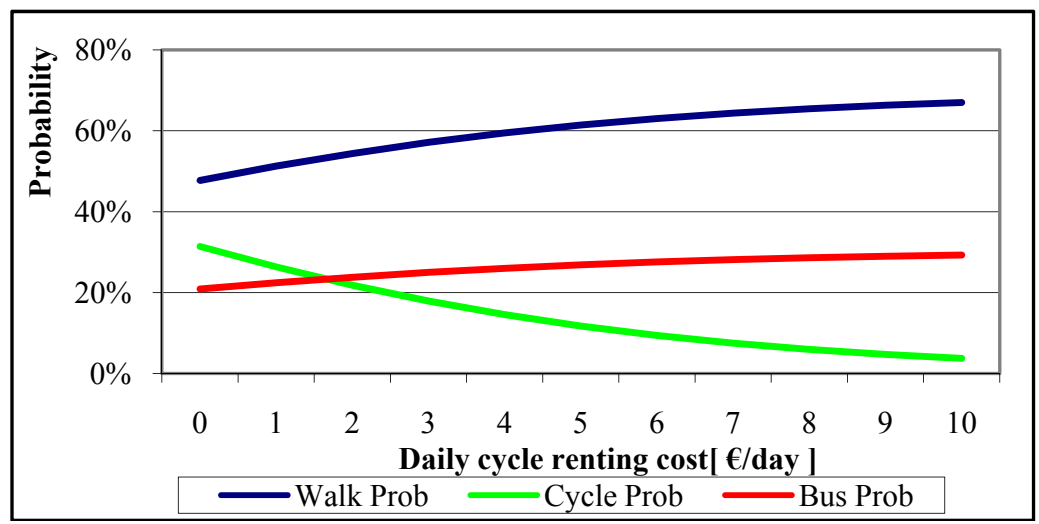

Figure 5: The probability choice for urban trips.

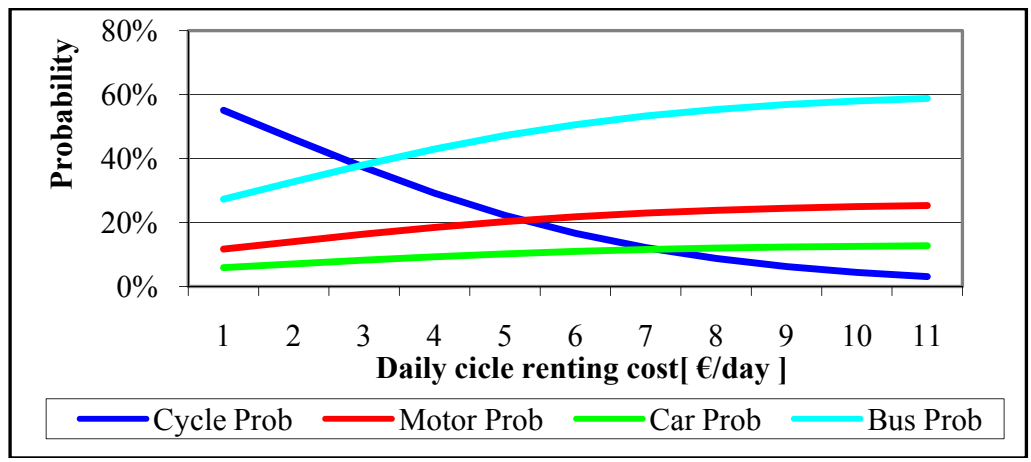

Figure 6: The probability choice for extra urban trips.

\section{Conclusion}

The methodological approach showed allows one to set up a framework to design the cycle paths based on the potential demand of cycling. Some critical factors can influence the viability of the cycle mode:

- $\quad$ the availability of separated cycle lanes from other traffic currents, reducing conflicting points and improving the road intersection;

- the rental service cost, it was shown that this attribute has influenced the probability choice of cycling;

- the integration with other modes and facilities to leave the bikes, especially near Transit/Railway stations in order to encourage transfers;

- the accessibility cycle paths, improving the road vertical and horizontal signs.

The attributes trip time and mean slope were not significant, whereas the lane was the most important attribute. Thus, the cycle user gives great importance to safety, considering crucial the separation of non-motorized traffic currents from 
motorized ones. The success of the cycle depends strictly on performances of any competitive transport mode. It was shown that the cycle users in particular tourist areas overcome their biases conversely to the big cities.

\section{References}

[1] AA. VV. 2000. Highway Capacity Manual. Transportation Research Board publications.

[2] Botma, H., 1995. Method to determine level of service for bicycle paths and pedestrian-bicycle paths. Transportation Research Record 1502, 38-44.

[3] Cleary, J., 1993. The Greater Nottingham demonstration cycle route project. In: Proceedings VeloCity'93 Conference, Nottingham, England.

[4] Davis J., 1987. Bicycle safety evaluation. Auburn University City if Chattanooga. Chattanooga, Tenn.

[5] Downing, C.S., 1980. Cycles safety. TRRL Supplementary Report 540, 1941, Transport and Road Research Laboratory, Crowthorne.

[6] Forester, J., 1983. Bicycle Transportation. The MIT Press, Cambridge, Massachusetts.

[7] Hudson, M., 1982. Bicycle Planning: Policy and Practice. The Architectural Press, London.

[8] Kocur G., Adler T., Hyman W., Aunet B., 1982. Guide to forecasting travel demand with direct utility assessment, United States Department of Transportation, Urban Mass Transportation Administration, Report UMTANH-11-0001-82-1, Washington DC,

[9] Newman, D., Bebendorf, M., 1983. Integrating bicycles and transit in Santa Barbara, California. Final Report to the Research and Special Programs Administration, US Department of Transportation, Transportation Systems Center, Cambridge, Massachusetts.

[10] Ortúzar J.D., Iacobelli A., Valeze C, 2000. Estimating demand for a cycleway network, Transportation Research A, 34, pp. 353-373.

[11] Ortuzar, J. de D., Willumsen, L.G., 1994. Modelling Transport, 2nd ed. Wiley, Chichester.

[12] Parking J., Wardman M., Page M., 2007. Models of perceived cycling risk and route acceptability, Accident Analysis and Prevention, 39 pp. 364-371.

[13] Replogle, M., 1983. Bicycles and Public Transportation: New Links to Suburban Transit Markets. Rodale Press, Emmaus, Pennsylvania.

[14] Waldman, J.A., 1977. Cycling in towns: a quantitative investigation. LRT 1 Working Paper 3, Department of Transport, London. 